\title{
Case study of simultaneous observations of sporadic sodium layer, E-region field-aligned irregularities and sporadic E layer at low latitude of China
}

Xie, H. Y. ${ }^{(1,2)}$, Ning, B. Q. ${ }^{(1,2)}$, Zhao, X. K. ${ }^{(1,3)}$ and Hu, L. H. ${ }^{(1,3)}$

(1) Beijing National Observatory of Space Environment, Institute of Geology and Geophysics, Chinese Academy of Sciences, Beijing, 100029, China

(2) State Key Laboratory of Space Weather, Chinese Academy of Sciences, Beijing, 100190, China

(3) Key Laboratory of Earth and Planetary Physics, Institute of Geology and Geophysics, Chinese Academy of Sciences, Beijing, 100029, China

Using the $\mathrm{Na}$ lidar at Haikou $\left(20.0^{\circ} \mathrm{N}, 110.3^{\circ} \mathrm{E}\right)$, the VHF coherent radar and the digital ionosonde both at Sanya $\left(18.4^{\circ} \mathrm{N}, 109.6^{\circ} \mathrm{E}\right)$, cases of simultaneous observations of sporadic sodium layer (SSL), E-region field-aligned irregularities (FAI) and sporadic E layer (Es) in the mesosphere and lower thermosphere (MLT) region at low latitude of China are studied. It is found that SSL occurs simultaneously or follows the enhancement of Es and FAI. The Es, FAI and SSL descend slowly with time which is mostly controlled by the diurnal tide (DT). Besides, the interaction of gravity wave (GW) with tides can cause oscillations in FAl and SSL. Our observations support the neutralization of ions for SSL formation: when the metallic ions layer descents to the altitudes where models predict, the sodium ions convert rapidly to atomic $\mathrm{Na}$ that may form an SSL event. Moreover, the SSL peak density will increase (decrease) in the convergence (divergence) vertical shear region of zonal wind. 